\title{
Mycoremediation of Monocyclic Aromatic Hydrocarbons by a Local Marine Aspergillus oryzae (Statistical Analysis of the Main and Substrate Interaction Effects)
}

Hala Y. El-Kassas and ${ }^{1}$ Eman M. El-Taher*

Hydrobiology Laboratory, Marine Environmental Division, National Institute of Oceanography \& Fisheries, Alexandria and ${ }^{*}$ The Regional Center for Mycology \& Biotechnology, AlAzhar University, Nasr City, Cairo, Egypt.

\begin{abstract}
N AROMATIC hydrocarbon utilizing fungus was isolated from a wastewater polluted sea spot in the Mediterranean, Alexandria, Egypt. It was identified to the species level as Aspergillus oryzae. The marine fungal isolate has the ability to remove BTHX compounds (benzene, toluene, hexylbenzene and xylene), concentrations ranged between 15 and $75 \mathrm{mgl}^{-1}$. Up to our knowledge, it is the first description of BTHX removal by a local marine strain of $A$. oryzae. The removal efficiencies of these compounds varied between 58 and $85 \%$, within $48 \mathrm{hr}$. Experiments were conducted according to the $2^{4}$ fraction fractorial design to identify the main and interaction effects of individual BTHX removal efficiency. A statistical interpretation of the results revealed that the main effect of benzene was significant $(P<0.05)$. High $F$ values for the 4-way interaction between different hydrocarbons with low $\mathrm{P}$ values suggest that the interactions between individual BTHX are the most significant factors. The negative interactions between benzene and hexylbenzene, benzene and xylene concentrations were found to be statistically significant $(\mathrm{P}<0.05)$. On the other hand, there was a positive significant interaction between hexylbenzene and xylene $(\mathrm{P}<$ 0.05 ). A successful trial showed very good applicability of the marine fungal isolate to remove $80.00,95.64$ and $89.00 \%$ of benzene, toluene and xylene, respectively, in the waste effluent of Alexandria Petroleum Company after $48 \mathrm{hr}$. This effluent contains very high concentrations of BTX compounds $\left(36.38 \mathrm{gl}^{-1}\right)$. Using the diluted effluent $(50 \%)$, the removal efficiency of the BTX reached distinct value of 97,98 and $98 \%$ for benzene, toluene and xylene, respectively, after $72 \mathrm{hr}$. These significant quantitative removal capacities demonstrate the potential application of marine A. oryzae for the mycoremediation of BTX compounds from waste water systems.
\end{abstract}

Keywords: BTHX mixture, Marine fungi, Fungal bioremediation, Removal efficiency, Statistical analyses.

Benzene, toluene, ethyl benzene and o-xylene, collectively known as BTEX, are toxic compounds commonly emitted into the environment due to their ubiquitous

Corresponding author e-mail address: halayassin12@yahoo.com

${ }^{1}$ E-mail address: eman 95-taher@hotmail.com 
presence in fuel and petroleum products. They are classified as environmental priority pollutants. Vehicular exhausts and industrial emissions are the major sources of ambient BTEX, in addition to the pollutants resulting from outside, in indoor air, household products and tobacco smoke, construction materials, heating, solvents and adhesives may increase BTEX concentrations (Jia et al., 2008). These hydrocarbon compounds are also produced on a large scale for industrial use as solvents and starting materials for the manufacture of pesticides, plastics, etc. ( Clavalca et al., 2000 ; Makkar \& Rockne, 2003 ; Nicholson \& Fathepure, 2004; Mattison et al., 2005 and Andreoni \& Gianfreda, 2007). BTHX are highly volatile and toxic substances, that are considered to be very important since they contribute generously to global environmental effects such as ozone layer depletion, greenhouse effects and acid rain (Jenkin \& Clemitshaw, 2000 ; Burgess et al., 2001 and Brigmon et al., 2002). Even at low concentrations, BTHX can cause damage to the liver and kidney and paralyze the central nervous system ( Martin et al., 1998 and Murata et al., 1999 and Pruden et al., 2003). Bioremediation, is an efficient, economic and a versatile treatment option to remove BTEX at various concentrations (Reardon et al., 2002). Also, mycoremediation may result in complete degradation of organic compounds to nontoxic byproducts. Filamentous fungi are known to be of potential degradative capabilities to many organic pollutants (Prenafeta-Bold'u et al., 2004). Although data on BTHX degradation by bacteria and substrate interactions are well documented (Amer et al., 2008 and Rene et al., 2007), analogous data for fungi are still very scarce (Prenafeta-Boldú et al., 2002). Because of their aggressive growth, greater biomass production and extensive hyphal growth, fungi offer potential for bioremediation technology. Fungi and other eukaryotes normally oxidize aromatic compounds using mono-oxygenase, forming a trans-diol (Saratale et al., 2007). Generally, BTHX compounds are often encountered as mixtures rather than as a single compound and the fate of these compounds is often strongly controlled by microbial activity (Mi-Seon et al., 2008).

Therefore, the present study was designed to isolate and identify a local marine fungus from hydrocarbon polluted sea area of the Mediterranean, Alexandria, Egypt. Moreover, to study its ability to remove mixtures of BTHX as a resistant and a cost effective mycoremediator. BTHX mycoremediation as mixtures was studied using the marine isolate in free (suspended) cell systems.

\section{Chemicals}

\section{Materials and Methods}

BTHX hydrocarbons included benzene (B), toluene $(\mathrm{T})$, hexylbenzene $(\mathrm{H})$ and xylene $(\mathrm{X})$ and medium components were purchased from Sigma-Aldrich Company, Germany. Other chemicals were of analytical grade.

\section{Sampling collection and isolation of marine fungi}

Sea water samples on a depth of half meter, were collected from a hydrocarbons polluted area in Mediterranean Sea, Alexandria, Egypt during April 2009. The culture medium described by Cooke (1963) with slight modification was used. 
The composition of medium $\left(\mathrm{gl}^{-1}\right)$ is: rose Bengal (3.0), glucose (10), peptone (5) and agar (15), sea water (1L). The medium was poured onto the samples within Petri dishes and the plates were allowed to solidify, and then incubated at $28{ }^{\circ} \mathrm{C}$ for 7 days. After the incubation period, species were isolated into pure culture and used for screening.

\section{Media composition}

The Mineral Salts Medium (MSM) described by Cunha et al. (2001) with the following composition $\left(\mathrm{gl}^{-1}\right)$ : $0.4 \mathrm{KH}_{2} \mathrm{PO}_{4} ; 0.2 \mathrm{MgSO}_{4} .7 \mathrm{H}_{2} \mathrm{O} ; 0.1 \mathrm{NaCl} ; 0.025$ $\mathrm{CaCl}_{2} .2 \mathrm{H}_{2} \mathrm{O} ; 0.003 \mathrm{MnSO}_{4} \cdot \mathrm{H}_{2} \mathrm{O} ; 0.5 \mathrm{NH}_{4} \mathrm{NO}_{3} .2 \mathrm{H}_{2} \mathrm{O} ; \mathrm{pH}(6)$ and Rose Bengal (3.0) and agar (15) was used. The medium was sterilized at $121^{\circ} \mathrm{C}$ for $15 \mathrm{~min}$. After autoclaving, hydrocarbons were added at a concentration of $45 \mathrm{mgl}^{-1}$ of individual BTHX as the sole carbon and energy sources and inoculated with a $3 \%$ of the fungal spores suspension. The most promising fungal isolate showing maximum BTHX removal was selected, identified and used throughout this study.

\section{Identification of the isolated fungus}

The most promising marine fungal isolate showing maximum BTHX removal was selected and identified to the species level where it subjected for certain morphological studies by an Image Analysis System using Soft-Imaging GmbH software (analysis Pro ver. 3.0) at the Regional Center for Mycology and Biotechnology (RCMB), Al-Azhar University, Cairo, Egypt, and by using the most documented keys in fungal identification (Domsch et al., 1993). Through the study period, the organism was routinely maintained at $4{ }^{\circ} \mathrm{C}$ on the mineral salts agar slants supplemented with $2 \%$ glucose.

\section{Scanning electron microscopy}

The fungal isolate was grown on Malt Extract Agar (MEA) medium as a control and on (MSM) medium amended with $300 \mathrm{mgL}^{-1}$ of BTHX (treated). It was prepared for fixation and dehydration procedures at RCMB according to Bozzola \& Russell (1999). The samples were dried completely in a critical point dryer and finally coated with gold in SPI-MODULE sputter coater. Then the specimens were viewed with a JEOL-JSM 5500LV.

\section{BTHX removal experiments}

Batch removal experiments were conducted by varying individual BTHX concentrations ranging between 15 and $75 \mathrm{mgl}^{-1}$ according to the statistically significant fractional factorial design. The experiments were conducted in $300 \mathrm{ml}$ glass bottles (working volume, $100 \mathrm{ml}$ ). BTHX was directly injected to this working volume corresponding to different initial concentrations and $3 \%$ of the fungal spore suspension was added. The resulting BTHX containing MSM was incubated in a rotary shaker at speed $150 \mathrm{rpm}$ and maintained at ambient temperatures $\left(28-30^{\circ} \mathrm{C}\right)$. Samples were collected after $48 \mathrm{hr}$ and analyzed for biomass and residual BTHX concentrations. The effect of substrate concentration on cell growth has been examined. Experiments were carried out 
at different initial concentrations of BTHX corresponding to total BTHX concentrations varying between 60 and $300 \mathrm{mgl}^{-1}$. These experiments were conducted as per the experimental plan outlined by fraction factorial design (Rene et al., 2007). The BTHX removal efficiency was calculated as follows:

Total BTHX removal $\% \frac{\text { Total BTHX, initial - Total BTHX, final }}{\text { Total BTHX initial }}$
Fra
ctio

$n$ factorial design of experiments

Experiments with different concentrations of BTHX were conducted using the experimental design obtained by $2^{4-1}$ fraction factorial design. It is a two level design (low and high values of the factor) which includes only a fraction of the total trial that comprise a full factorial design (Montgomery, 1991). It consists of $2^{4-1}$ runs (trials), where ' 2 ' represent the two levels of the factor and ' 4 ' is the total number of factors. Moreover, when high order interactions are negligible, reasonable information on the main effects and low order interactions may be obtained by running only a fraction of the complete factorial design. Hence, $2^{(4-1)}$ design is a fraction of the $2^{4}$ full fractional designs that consist of 8 runs instead of 16 with 2 center-point replicates (Rene et al., 2007). Coded levels and actual values of the variables investigated in this study are given in Table 1. Statistical analyses were performed with the software Minitab (Version 14).

TABLE 1. A $2^{4}$ fraction factorial design with two center point replicates employed in BTHX removal by marine $A$. oryzae.

\begin{tabular}{|c|c|c|c|c|}
\hline \multirow{2}{*}{ Experiment run no. } & \multicolumn{5}{|c|}{ Concentration of individual substrates } \\
\cline { 2 - 5 } & $\left.\mathbf{m g l} \mathbf{l}^{\mathbf{1}}\right)$ & $\mathbf{H}$ \\
\cline { 2 - 5 } & $\mathbf{B}$ & $\mathbf{T}$ & $\mathbf{H}$ & $\mathbf{X}$ \\
\hline 1 & -1 & -1 & -1 & -1 \\
\hline 2 & +1 & -1 & -1 & +1 \\
\hline 3 & -1 & +1 & -1 & +1 \\
\hline 4 & +1 & +1 & -1 & -1 \\
\hline 5 & -1 & -1 & +1 & +1 \\
\hline 6 & +1 & -1 & +1 & -1 \\
\hline 7 & -1 & +1 & +1 & -1 \\
\hline 8 & +1 & +1 & +1 & +1 \\
\hline 9 & 0 & 0 & 0 & 0 \\
\hline 10 & 0 & 0 & 0 & 0 \\
\hline
\end{tabular}

-1: Low level $\left(15 \mathrm{mgl}^{-1}\right),+1$ : High level $\left(75 \mathrm{mgl}^{-1}\right) \quad 0$ : Center point of the factors $\left(45 \mathrm{mgl}^{-1}\right)$.

\section{Mycoremediation of BTHX in the final waste effluents of Alexandria Petroleum} Company using marine A. oryzae

The applicability of the marine A. oryzae to take up BTHX mixture in an industrial waste was tested. Samples of the final waste effluent of Alexandria Petroleum Company were collected from the region of waste discharge at the sea shore. The experiments were conducted as previously described using $3 \%$ of the fungal spore suspension, incubated in a rotary shaker at $150 \mathrm{rpm}$ and maintained at ambient temperatures $\left(28-30^{\circ} \mathrm{C}\right)$. The samples without any additives were used

Egypt. J.Microbiol. 45 (2010) 
as a growth medium, other trials using the diluted samples were carried out and the BTHX removal percentages were recorded after 48 and $72 \mathrm{hr}$.

Gas chromatography analyses of aromatic hydrocarbons

Aromatic hydrocarbons were extracted from cultures by n-hexane at ratio of 1:5 n-hexane : media. The extracted hydrocarbons and standards were injected to a GC/FID GC-5890, series II. Auto-sampler Shimadzu C20i using RTX-5 column (length $15 \mathrm{~m}$, internal diameter $0.25 \mathrm{~mm}$ and film thickness $0.26 \mu \mathrm{m})$, linear velocity was $49 \mathrm{~cm} \mathrm{sec}^{-1}$. Nitrogen was used as a carrier gas at a flow rate of $2 \mathrm{ml} \mathrm{min}^{-1}$. The detector and injector temperatures were 300 and $250^{\circ} \mathrm{C}$, respectively and the oven temperature was maintained at $325^{\circ} \mathrm{C}$ (Bielefeldt \& Stensel, 1999 a, b). All GC analyses were carried out in the central laboratory of the National Institute of Oceanography and Fisheries (NIOF), Alexandria, Egypt.

\section{Results}

Identification and measurements of the locally isolated marine fungus with and without BTHX

The results revealed that the isolated organism was identified up to the species level as A. oryzae. Measurements of its vesicle, phialides (length and width) and conidial dimensions are shown in Table 2 and the scanning electron micrographs are presented in Fig 1.

TABLE 2. Characteristics of A. oryzae dimensions, before (control) and after growth on the mixture of (BTHX).

\begin{tabular}{|l|c|c|c|}
\hline & $\begin{array}{c}\text { Vesicle } \\
(\boldsymbol{\mu} \mathbf{m})\end{array}$ & $\begin{array}{c}\text { Phialides }(\mathbf{L} \times \mathbf{W}) \\
(\boldsymbol{\mu} \mathbf{m})\end{array}$ & $\begin{array}{c}\text { Conidia } \\
(\boldsymbol{\mu} \mathbf{m})\end{array}$ \\
\hline Control & 43.8 & $12.0 \times 3.0$ & 4.64 \\
\hline & & & \\
\hline After growth on (BTHX) & 43.7 & $11.0 \times 2.6$ & 4.23 \\
\hline
\end{tabular}



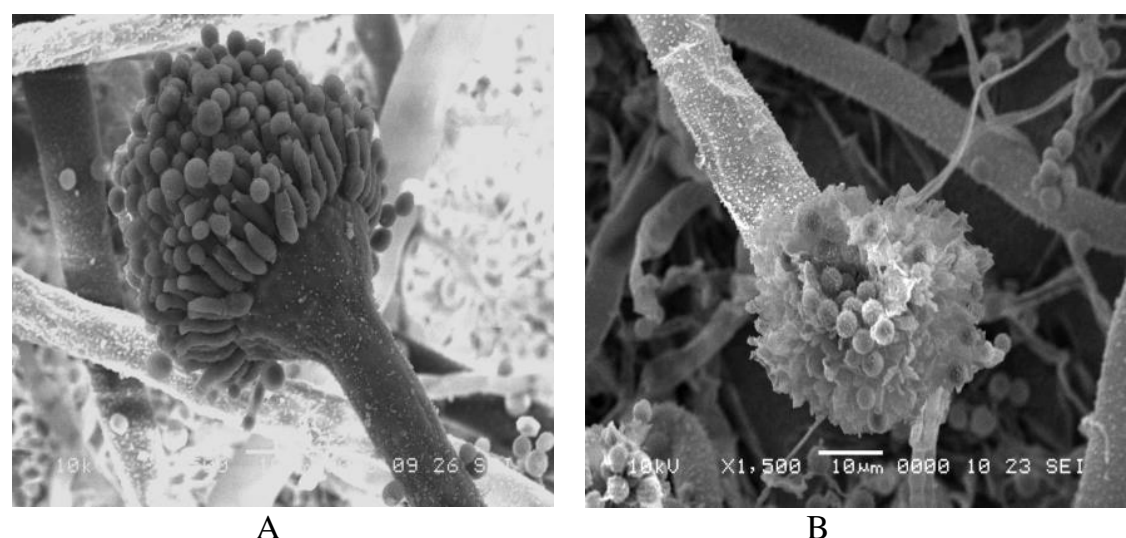

Fig. 1. Scanning electron micrographs of the marine A. oryzae before (A) and after (B) growth on BTHX (x1500).

\section{Batch biodegradation tests}

The biomass growth profile and substrate utilization pattern observed for the marine isolate while utilizing BTHX as the sole carbon source is shown in Table 3. The removal pattern and extent of growth seem to be a function of the initial concentration of different substrates. These data revealed that the fungal isolate showed the best removal of total BTHX $(85 \%)$ and the biomass concentration $\left(12.8 \mathrm{gl}^{-1}\right)$ were achieved with the highest level of the compounds (run no. 8). However, the lowest removal value $(58 \%)$ and biomass $\left(7.6 \mathrm{gl}^{-1}\right)$ were observed with the experimental run no 5 when hexylbenzene and xylene were presented in their high level (75 $\mathrm{mg} \mathrm{l}^{-1}$, each).

TABLE 3. Removal efficiency percentage of total BTHX and biomass growth profile $\left(\mathrm{gl}^{-1}\right)$ after $48 \mathrm{hr}$ of marine $A$. oryzae growth in liquid mineral media amended with different concentrations of BTHX as a sole carbon and energy source.

\begin{tabular}{|c|c|c|}
\hline Experiment run no & $\begin{array}{c}\text { Removal of total } \\
\text { BTHX } \\
(\mathbf{\%})\end{array}$ & $\begin{array}{c}\text { Biomass concentrations } \\
\mathbf{g l}^{\mathbf{1}}\end{array}$ \\
\hline 1 & 81 & 10.7 \\
\hline 2 & 68 & 8.60 \\
\hline 3 & 61 & 8.10 \\
\hline 4 & 77 & 9.06 \\
\hline 5 & 58 & 7.60 \\
\hline 6 & 78 & 9.9 \\
\hline 7 & 82 & 11.20 \\
\hline 8 & 85 & 12.80 \\
\hline 9 & 73 & 8.80 \\
\hline 10 & 73 & 8.80 \\
\hline
\end{tabular}

Egypt. J.Microbiol. 45 (2010) 
Data in Fig . 2 depict that the removal percentage of each compound in the mixture varied with the initial concentration used in each experimental run. Generally, benzene and toluene removal were not greatly affected, whereas an obvious variation was noticed with hexylbenzene and xylene.

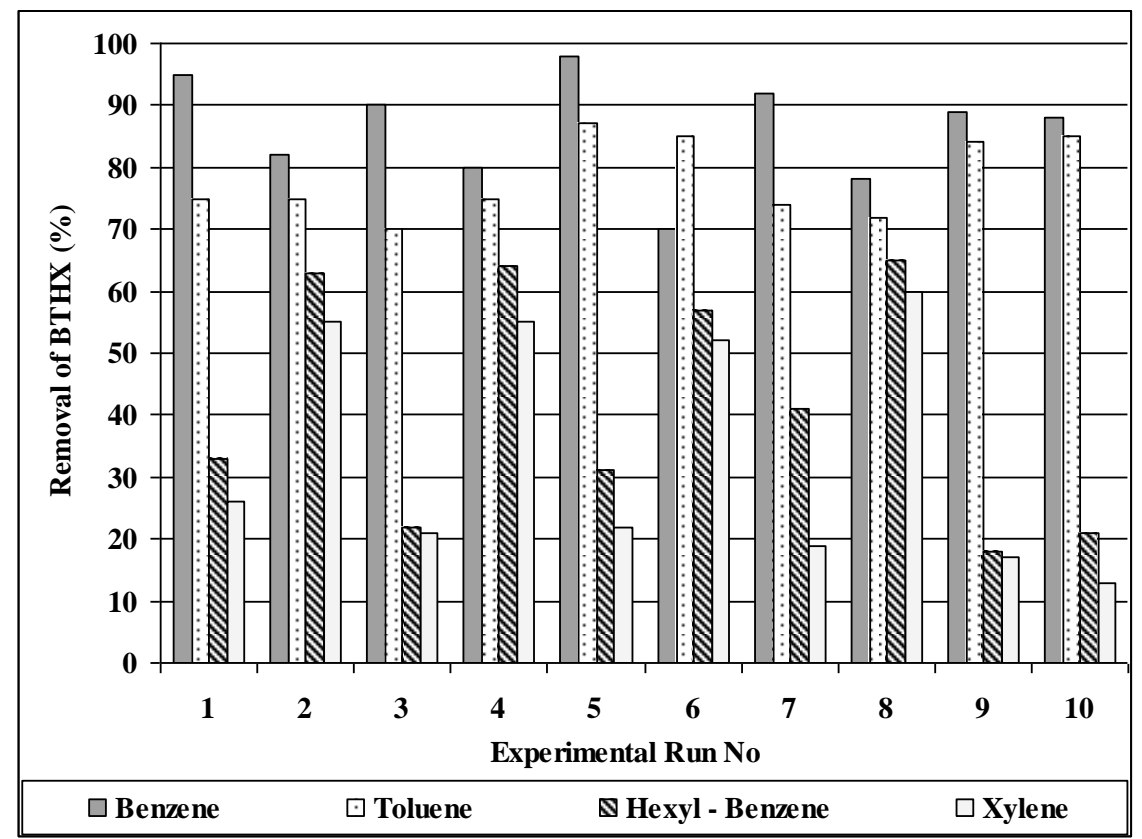

Fig. 2. Removal efficiency percentage of individual (BTHX) components by marine A. oryzae during different experimental runs.

The correlation matrix (Table 4) reveals that the negative interaction effects exist between benzene and hexylbenzene as well as benzene and xylene, however the positive interaction effects between hexyl-benzene and xylene were found to be significant to the model $(\mathrm{P}<0.05)$. There were insignificant negative interaction effects between toluene removal efficiency and that of hexylbenzene as well as xylene $(r=-0.33$ and $r=-0.30)$, respectively.

TABLE 4. Correlations matrix between individual BTHX removal by marine A. oryzae.

\begin{tabular}{|l|c|c|c|c|}
\hline & Benzene & Toluene & $\begin{array}{c}\text { Hexyl- } \\
\text { Benzene }\end{array}$ & Xylene \\
\hline Benzene & 1.00 & & & \\
\hline Toluene & 0.05 & 1.00 & & \\
\hline $\begin{array}{l}\text { Hexyl- } \\
\text { Benzene }\end{array}$ & $\underline{-0.71}$ & -0.33 & 1.00 & \\
\hline Xylene & $\underline{-0.79}$ & -0.30 & $\underline{0.95}$ & 1.00 \\
\hline
\end{tabular}

$\mathrm{p}<0.05$; the correlation values ( $\mathrm{r}$ ) are significant when $\mathrm{r}>0.70$ (underlined). 
The results indicated that high $\mathrm{F}$ values for the 4-way interaction between different hydrocarbons with low $\mathrm{P}$ values suggests that the interactions between individual BTHX are the most significant factors affecting BTHX removal efficiency by marine A. oryzae, (Fig. 3 and Table 5).

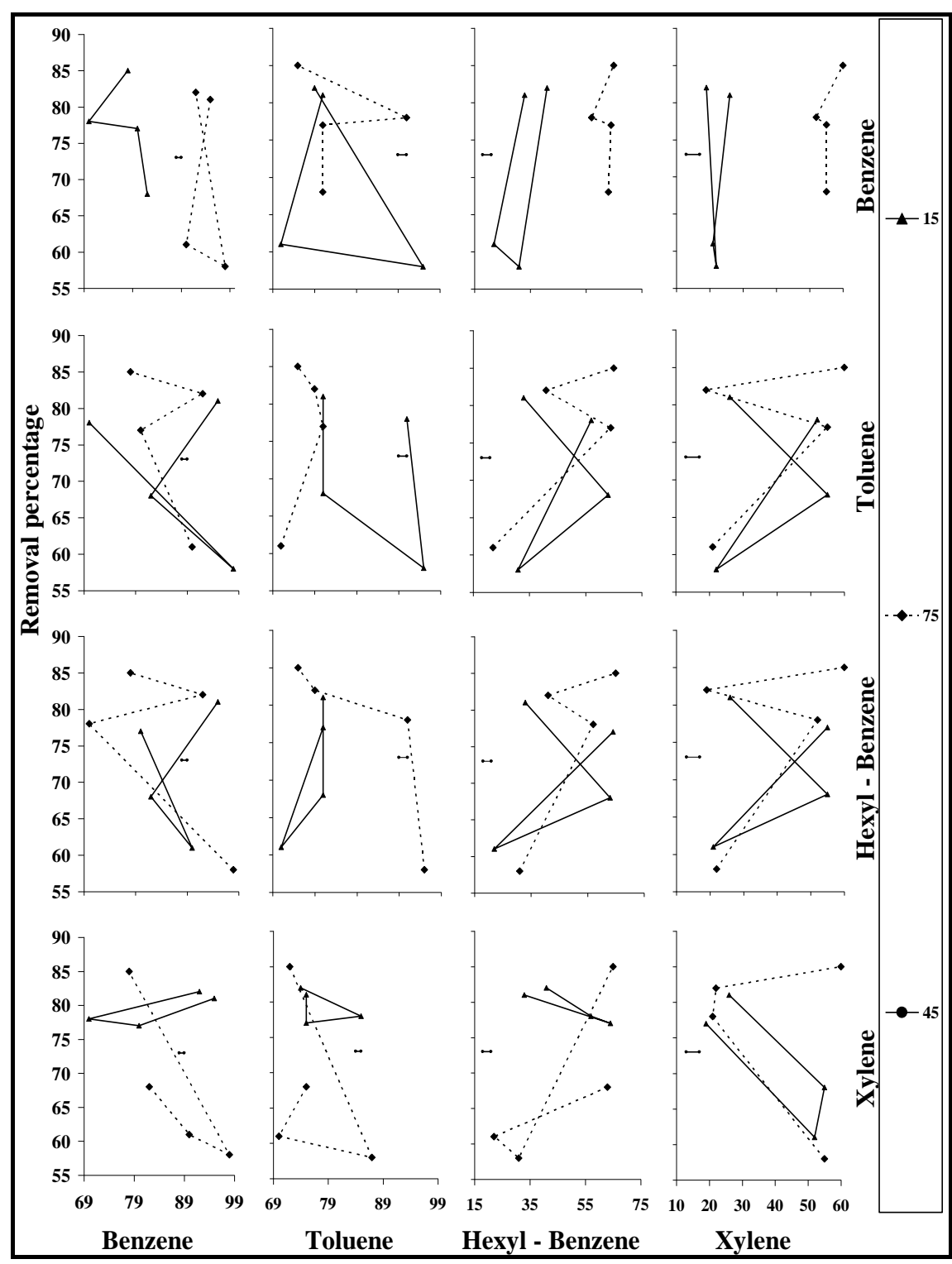

Fig. 3. Interaction plot for BTHX removal by marine A. oryzae (BTHX concentration, $\mathrm{mgl}^{-1}$ ) .

Egypt. J.Microbiol. 45 (2010) 
TABLE 5 Factorial analysis of variance for total BTHX removal by marine $A$. oryzae.

\begin{tabular}{|c|c|c|c|}
\hline & Main effects & $\begin{array}{c}\text { 2-way } \\
\text { interactions }\end{array}$ & $\begin{array}{c}\text { 4-way } \\
\text { interactions }\end{array}$ \\
\hline Benzene & $278.25^{*}$ & F & F \\
\hline Toluene & 94.75 & 60.92 & 26.45 \\
\hline Hexylbenzene & 106.17 & 45.58 & $198.45^{*}$ \\
\hline Xylene & 70.34 & 12.67 & $286.89^{*}$ \\
\hline
\end{tabular}

*: significant at $\mathrm{p}<0.05$, level of confidence $(\mathrm{P}<0.05)$.

Mycoremediation of BTHX in the final waste effluent of Alexandria Petroleum Company using marine A oryzae

Data presented in Table 6 reveal that total BTHX concentration in the waste effluent under investigation was very high compared with the used BTHX values in the design, being $36.38 \mathrm{gl}^{-1}$, the individual $\mathrm{B}, \mathrm{T}, \mathrm{H}$ and $\mathrm{X}$ were 20 , $4.38,0.00$ and $12 \mathrm{gl}^{-1}$, respectively.

TABLE 6. Concentrations of individual BTHX in the final waste effluent of Alexandria Petroleum Company $\left(\mathrm{gl}^{-1}\right)$.

\begin{tabular}{|c|c|}
\hline BTHX members & Concentration $\mathbf{~ ( g l ~}^{\mathbf{- 1}}$ ) \\
\hline Benzene & 20.00 \\
\hline Toluene & 4.38 \\
\hline Hexylbenzene & 0.00 \\
\hline Xylene & 12.00 \\
\hline Total BTHX & 36.38 \\
\hline
\end{tabular}

The results presented in Table 7 revealed that the marine fungal isolate had unexpected ability to remove $80 \%, 95.64 \%$ and $89 \%$, of $\mathrm{B}, \mathrm{T}$ and $\mathrm{X}$, respectively, in the waste effluent after $48 \mathrm{hr}$. Increasing the contact time between the fungal isolate and the waste resulted in an appreciable BTX removal 
to be $(94 \%, 98 \%$ and $96 \%)$ of $\mathrm{B}, \mathrm{T}$ and $\mathrm{X}$, respectively, after $72 \mathrm{hr}$. Using the diluted effluent $(50 \%)$, supreme removal efficiencies of the BTX compounds recorded 97,98 and $98 \%$ for $\mathrm{B}, \mathrm{T}$ and $\mathrm{X}$, respectively, after the same contact hours.

TABLE 7. Time course removal efficiency of BTX in the final waste effluent of Alexandria Petroleum Company using marine A. oryzae at different initial concentrations.

\begin{tabular}{|c|c|c|c|c|c|c|}
\hline \multirow{2}{*}{$\begin{array}{c}\text { Time } \\
\text { course }\end{array}$} & \multicolumn{3}{|c|}{ Waste } & \multicolumn{3}{c|}{ Diluted waste (50\%) } \\
\cline { 2 - 7 } & $\mathrm{B}$ & $\mathrm{T}$ & $\mathrm{X}$ & $\mathrm{B}$ & $\mathrm{T}$ & $\mathrm{X}$ \\
\hline After $48 \mathrm{hr}$ & 80.00 & 95.64 & 89.00 & 88.00 & 98.00 & 94.00 \\
\hline After 72 hr & 94.00 & 98.00 & 96.00 & 97.00 & 98.00 & 98.00 \\
\hline
\end{tabular}

Discussion

In this study, a statistically designed system was described in which spores of the local marine fungal isolate $A$. oryzae had a remarkable ability to grow well and germinat on a complex mixture of BTHX hydrocarbons as the sole carbon and energy sources in Minimal Salts Medium (MSM). Interestingly, to our knowledge this is the first report of a local marine fungal isolate growing on monocyclic aromatic hydrocarbons, which included four BTHX components. Most of the previous researches in this field had focused on aerobic bacteria growing on BTEX mixtures (Rene et al., 2007 and Amer et al., 2008). This BTHX solution was comparable to a real gasoline water-soluble fraction as indicated by Saeed \& Al Mutairi (1999). Distortion of the marine fungal morphology reported in the current study could be attributed to the water stress induced by BTHX. In this respect, Hallsworth et al. (1998) reported that water stress may account for considerably more than $30 \%$ of growth inhibition of $A$. oryzae by ethanol in cells that remain metabolically active at higher ethanol concentrations.

At experimental run number eight, $85 \%$ of the total BTHX were removed. Similarly, Prenafeta-Boldú et al. (2002) found that the fungus Cladophialophora sp. strain T1 possessed a metabolic capacity for BTEX removal. The total removal of BTHX by the marine $A$. oryzae was dependent on the initial concentration of each compound in the mixture. Their individual removal efficiencies showed a varied response depending on the initial concentrations of other substrates (Rene et al., 2007).

In this study, statistical experimental design was employed. These designs have many advantages and were used in many successful degradative studies (Saravanan et al., 2008). Compared to conventional one factor at a time experiments, statistical based factorial design of experiments gave more meaningful information on the effects, main and interaction, of the factor

Egypt. J.Microbiol. 45 (2010) 
involved in a given study. Moreover, the added advantage of reduction in the number of experiments to be performed is remarkable. Employing such techniques proves more attractive for systematic investigations without compromising the accuracy of representation of the environmental system (Montgomery, 2004). On the other hand, single variable optimization methods are not only tedious, but also can lead to misinterpretation of results, especially because the interaction effects between different factors are overlooked (Wenster-Botz, 2000).

The correlation matrix obtained for each individual BTHX component was consistent with the utilization pattern seen in a complex BTHX mixture, where benzene and toluene were consumed preferentially, followed by hexylbenzene and finally xylene, which was hardly consumed. At high levels of benzene and xylene as well as benzene and hexylbenzene concentrations, there exists a significant interaction. All other interactions were insignificant within the range of BTHX concentrations tested. Factorial analysis of variance for BTHX removal by marine A. oryzae reveals that the main effect of benzene and the 4way interactions between individual BTHX are the most significant factors affecting BTHX removal efficiency by marine A. oryzae. Similarly, PrenafetaBoldú et al. (2002) reported substrate interactions during the biodegradation of benzene, toluene, ethyl benzene, and xylene (BTEX) hydrocarbons by the fungus Cladophialophora sp. strain T1.

The interactions between benzene and hexylbenzene concentrations as well as that between benzene and xylene significantly reduced BTHX removal in mixtures. Strong competition might induce a sequential pattern for the utilization of the different substrates, a phenomenon usually referred as diauxie, which makes treatment of mixtures in a continuous system difficult. Diauxie during BTHX degradation has been described, for example, for a Rhodococcus strain (Deeb \& Alvarez-Cohen, 1999). The prime reason for antagonistic effects during BTHX degradation in mixtures can be attributed to competitive inhibition (Chang et al., 1993; Oh et al., 1994 and Bielefeldt \& Stensel, 1999 b), toxicity (Haigler et al., 1992) and the formation of toxic intermediates by non-specific enzymes (Mi-Seon et al., 2008).

In conclusion, the present study clearly demonstrated that marine fungi had the ability to grow on aromatic hydrocarbons. They prove and reflect their potentialities in bioremediation of BTHX pollution. At present, a great deal of attention in the field of fungal bioremediation is being paid to the development of fungal biofilters for the treatment of hydrocarbons contaminated wastewater.

Acknowledgements: Grateful thanks to Professor / Sorya Sabry, Department of Botany and Microbiology, Faculty of Science, Alexandria University for her kind help and revision of this work and to Professor / Mosaad Abdel Wahab, National Research Centre, Dokki for his valuable proof reading of the article. 


\section{References}

Amer, R.A., Nasier, M.M. and El-Helow, E.R. (2008) Biodegradation of monocyclic aromatic hydrocarbons by a newly isolated Pseudomonas strain. Biotechnology, 7, 630-640.

Andreoni, V. and Gianfreda, L. (2007) Bioremediation and monitoring of aromaticpolluted habitats. Appl. Microbiol. Biotech. 76, 287-308.

Bielefeldt, A.R. and Stensel, H.D. (1999a) Evaluation of biodegradation kinetic testing methods and long term variability in biokinetics for BTEX metabolism. Water Res., 33, 733-740.

Bielefeldt, A.R. and Stensel, H.D. (1999b) Modeling competitive inhibition effects during biodegradation of BTEX mixtures. Water Res. 33, 707-714.

Brigmon, R.L., Camper,D. and Stuzenberger, F. (2002) Bioremediation of compounds hazardous to health and the environment- an overview. In: "Biotransformation: Bioremediation Technology for Health and Environment Protection," Sigh, V.P., Stapleton, R.D. (Ed.). pp. 1-28. Elsevier Science Publishers. The Netherlands.

Bozzola, J.J. and Russell, L.D. (1999) "Electron Microscopy: Principles and Techniques for Biologists," $2^{\text {nd }}$ ed., Jones and Bartlett Publishers, Massachusetts, USA.

Burgess, J.E., Parsons, S.A. and Stuetz, R.M. (2001) Developments in odour control and waste gas treatment biotechnology: A review, Biotech. Adv. 19, 35-63.

Chang, M.K., Vtoice, T.C. and Criddle, C.S. (1993) Kinetics of competitive inhibition and co- metabolism in the biodegradation of benzene, toluene, and p-xylene by two Pseudomonas isolates. Biotech. Bioeng. 41, 1057-1065.

Clavalca, L., Gennaro, P., Colombo, M., Andereoni, V., Bernasconi, S., Ronoc, I. and Bestetti, G. (2000) Distribution of catabolic pathways in some hydrocarbondegrading bacteria from subsurface polluted soil. Res. J. Microbiol. 151, 877-887.

Cooke, W.B. (1963) A Laboratory Guide to Fungi in Polluted Waters, Sewage and Sewage Treatment Systems: Their Identification and Culture. Cincinnati, Ohio: U.S. Department of Health, Education and Welfare. p132.

Cunha, C., Rosário, M., Rosado, A. and Leite, S. (2001) Screening of microorganisms with potential to produce biosurfactants in the presence of gasoline. In. Proceedings of XXI Congresso, Brasileiro de Microbiologia held at Foz do Iguaçu, Brazil, Foz do Iguaçú: SBM, p. 362.

Deeb, R.A. and Alvarez-Cohen, L. (1999) Temperature effects and substrate interactions during the aerobic biotransformation of BTEX mixtures by toluene-enriched consortia and Rhodococcus rhodochrous. Biotech. Bioeng. 62, 526-536.

Domsch, K.H., Gams, W. and Anderson, T. (1993) "Compendium of Soil Fungi." Vol.I, II, pp. 405, 859, reprint IHW Verlag, Eching, Germany, 
Haigler, B.E., Pettigrew, C.A. and Spain, J.C. (1992) Biodegradation of mixtures of substituted benzenes by Pseudomonas sp. strain JS150. Appl. Environ. Microbiol. 58, 2237-2244.

Hallswoth, H., Nomura, Y. and Iwahara, M. (1998) Ethanol-induced water stress and fungal growth. J. Ferment. Bioeng. 86, 451-456.

Jenkin, M.E. and Clemitshaw, K.C. (2000) Ozone and other secondary photochemical pollutants: Chemical processes governing their formation in the planetary boundary layer, Atm. Environ. 34, 2499-2527.

Jia, C., Batterman, S. and Godwin, C. (2008) VOCs in industrial, urban and suburban neighborhoods-Part 2: Factors affecting indoor and outdoor concentrations Atm. Environ. 42, 2101-2116.

Makkar, R. and Rockne, K. (2003) "Comparison of synthetic surfactants and biosurfactants in enhancing biodegradation of polycyclic aromatic hydrocarbons" Environ. Toxicol. Chem. 22, 2280-2292.

Martin, M., Keuning, S. and Janssen, D. (1998) "Handbook on Biodegradation and Biological Treatment of Hazardous Organic Compounds", $2^{\text {nd }}$ ed., Academic Press, Dordrecht.

Mattison, R., Taki, H. and Harayama, S. (2005) The soil flagellate Heteromita globosa accelerates bacterial degradation of alkyl-benzenes through grazing and acetate excetion in batch culture. Microbiol. Ecology, 49, 142-150.

Mi-Seon, J., Rene, E., Kim, S. and Park, H. (2008) An analysis of synergistic and antagonistic behavior during BTEX removal in batch system using response surface methodology. J. Hazard. Mat. 152, 1276-1284.

Montgomery, D. (1991) "Design and Analysis Experiments", $3^{\text {rd }}$ ed., Wiley, New York. 6.

Montgomery, D.C. (2004) "Design and Analysis of Experiments". $5^{\text {th }}$ ed., New York: John Wiley \& Sons.

Murata, M., Tsujikbawa, M. and Kawanishi, S. (1999) Oxidative DNA damage by minor metabolites of toluene may lead to carcinogenesis and reproductive dysfunction, Biochem. Bioph. Res. Comm. 261, 478-483.

Nicholson, C. and Fathepure, B. (2004) Biodegradation of benzene by halophilic and halo-tolerant bacteria under aerobic conditions. Appl. Environ. Microbiol. 70, 12221225 .

Oh, Y.S., Shareefdeen, Z., Baltzis, B.C. and Bartha, R. (1994) Interaction between benzene, toluene and p-xylene (BTX) during their biodegradation. Biotechnol. Bioeng. 44, 533-538.

Prenafeta-Boldú, F.X., Vervoort, J., Grotenhuis, J.T.C. and Van Groenestijn, W.J. (2002) Substrate interactions during the biodegradation of benzene, toluene, ethyl benzene and xylene hydrocarbons by the fungus Cladophialophora sp. strain T1., Appl. Environ. Microbiol. 68, 2660-2665. 
Prenafeta-Bold'u, F. X., Ballerstedt, H., Gerritse, J. and Grotenhuis, J.T.C. (2004) Bioremediation of BTEX hydrocarbons: Effect of soil inoculation with the toluenegrowing fungus Cladophialophora sp. strain T1. Biodegrad. 15, 59-65.

Pruden, A., Sedran, M., Suidan, M. and Venosa, A. (2003) Biodegradation of MTBE and BTEX in an aerobic fluidized bed reactor. Water Sci. Tech. 47, 123-128.

Reardon, K.F., Douglas, C.M., Julia, B.R., Nancy, M.D. and Kim, K.H. (2002) Biodegradation kinetics of aromatic hydrocarbon mixtures by pure and mixed bacterial cultures. Environ. Heal. Perspec. 110 (6).

Rene, E.R., Jo, M.S., Kim, S.H. and Park, H.S. (2007) Statistical analysis of main and interaction effects during the removal of BTEX mixtures in batch conditions, using wastewater treatment plant sludge microbes. Int. J. Environ. Sci. Tech. 4, 177-182.

Saeed, T. and Al Mutairi, M. (1999) Chemical composition of the water-soluble fraction of the leaded gasolines in seawater. Environ. Int. 25,117-129.

Saratale, G., Kalme, S., Bhosale, S. and Govindwar, S. (2007) Biodegradation of kerosene by Aspergillus ochraceus NCIM-1146. J. Basic Microbiol. 47, 400-405.

Saravanan, P., Pakshirajan, K. and Saha, P. (2008) Kinetics of phenol and $m$-cresol biodegradation by an indigenous mixed microbial culture isolated from a sewage treatment plant. J. Environ. Sci. 20, 1508-1513.

Wenster-Botz, D. (2000) Experimental design for fermentation media development: Statistical design or global random search? J. Biosci. Bioeng. 90, 473-483. 


\section{التحلل الحيوى لهيدروكريونِ عطري احادى الحلقة بواسطة فطرة

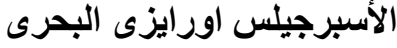 (تحليل إحصائي لتأثيراتِ تفاعلِ الركيزةِ الرئيسيةِِ والبيئة)}

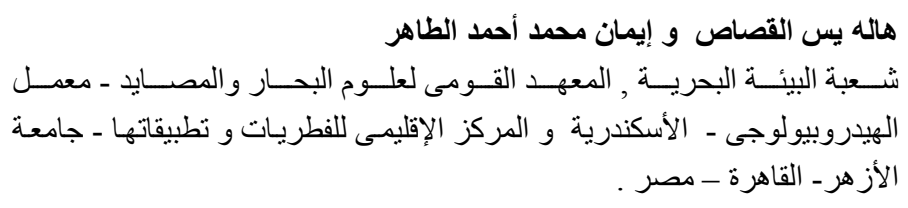

تم عزل فطر اً مِنْ بقعةَ مياه ملوّتثة في البحر الأبيض المتوسطِ، الأسكندرية مصر

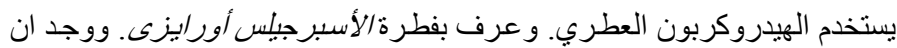

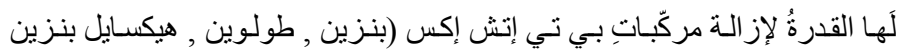

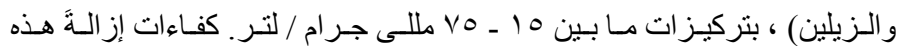

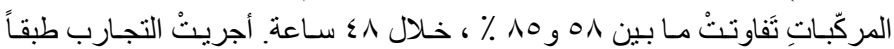

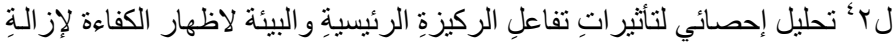

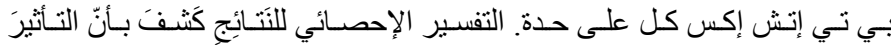

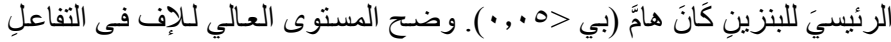

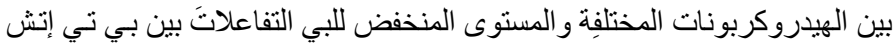

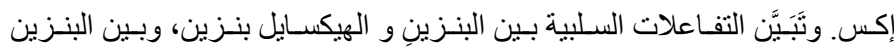

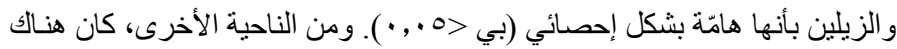

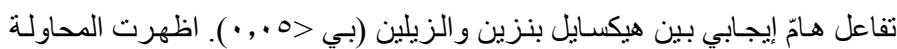

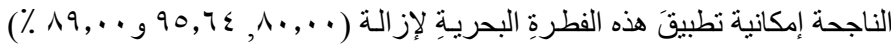

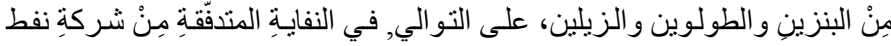

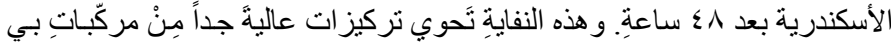

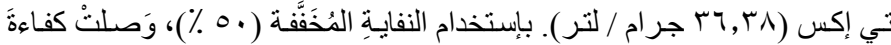

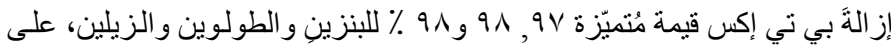

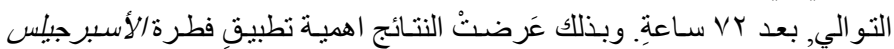
اورايزى البحرية لإز الةِ مركبات بي تي إكس مِنْ أنظمةِ المياه الملوّثة. 